\title{
The Depictions of the Cosmos in Popular Culture: in Searching of the Sense of Wholeness
}

\author{
Roman Sapeńko \\ Doctor of Science (Philosophy), Professor, University of Zielona Góra (Zielona Góra, \\ Poland) \\ E-mail: R.Sapenko@ifil.uz.zgora.pl \\ https://orcid.org/0000-0002-9663-3640
}

\section{Bogdan Trocha}

\author{
Doctor of Science (Philology), Professor, University of Zielona Góra \\ (Zielona Góra, Poland) \\ E-mail: bwtrocha@gmail.com \\ https://orcid.org/0000-0003-2348-4813
}

The aim of this paper is the recognition of the basic forms of depiction of the cosmos in popular culture, in particular in literature and film. By showing the premises underlying procedures of artistic creations, the authors also draw up proprietary strategies thanks to which the presented worlds are characterized by their entirety and integrity. For achievement of this purpose, they show the non-artistic and non-aesthetic sources of the cosmic representations/ imagery. The authors show the consequence of the inescapable inhomogeneity of the image of the cosmos in fantasy, and secondly they analyze how strategies associated with the scientific vision of the cosmos are closer to a rational worldview and how they bring the massive public the latest advances in cosmology, astronomy and quantum physics.

It is proved that that contemporary popular art is increasingly closely related to the modern state of scientific research in both the exact sciences and broadly understood religious studies or anthropology. The cosmos, thanks to popular creativity, becomes an acceptable, open and comprehensible space, while not being the most important challenge and mystery for humankind.

The results obtained the numbers of tools in artistic criticism and sphere of humanistic reflection and journalism in branch of popular culture. They enable a better understanding of the mechanisms of popularity of fantastic creativity and its impact on the recipient's awareness and give important tools in the process of popularizing the latest scientific discoveries.

Keywords: the Universe, Speculative fiction, Fantasy, Science fiction, Image of the Cosmos, Popular Culture

Received: January 15, 2019; accepted: March 18, 2019

Philosophy and Cosmology, Volume 23, 2019: 168-177.

https://doi.org/10.29202/phil-cosm/23/16

(C) Sapeńko, Roman, 2019

(C) Trocha, Bogdan, 2019 


\section{Introduction. The sources of imaginations of the Cosmos in speculative fiction}

Authors research methodology is based on results of contemporary studies in field of Philosophy and Cosmology represented by Oleg Bazaluk [Bazaluk, 2017], Volodymyr Pryhodko [Pryhodko, 2018], Olena Polischuk [Polischuk, 2018], Iryna Liashenko [Liashenko, $2018]$.

Trying to describe the ways of constructing the forms of the Cosmos, we should initially indicate the framework in which these analyzes would be carried out. This referring above all to the very understanding of the notion of speculative fiction. Etymologically, it originates from classical Greek and can mean both an empty product of imagination or dreams and intellectual mediation as well. Contemporary authors of fantasy works use imagination to create a variety of imaginary worlds. Basically, it can be assumed that they use a fantastic imagination in three not always related planes. The first one treats fantasy as simple forms of the imagination, which basic function is lucidity. In this case is completely irrelevant whether these images contain any cognitive content. One can even accept Samuel Taylor Colerdig's opinion that it is empty fantasy [eNotes, 15 Mar. 2010]. The second type of fantasy is proposed by Roger Caillois [Caillois, 2005] and it is just that model in the assumption break a rational image of the world. They force the recipient to adopt a new intellectual and emotional attitude towards the vision created by the artist that turns out for the audience the "scandal of reason." The third type of fantasy is present in the reflection of the outstanding Romanian religious scholar Mircea Eliade [Eliade 1993] and includes shapes of the imagination mediated by the content present in religious experience. Consequently, fantastic creativity can create shapes directed to pure aesthetic appeal and to speculative or cognitive content that cannot be expressed in a real and objective form.

Due to the specifics of fantastic images so outlined, it should be stated at the outset that fantastic works have been present in culture from the very beginning of mankind. It means that the fantastic fshapes of the universe present in contemporary culture have their sources also in eldest cultural text. Due to the fact that speculative fiction in the world of popular culture is essentially divided into fantasy and Science Fiction, it seems reasonable to analyze the source models used by the authors of these two types of creativity. The first model is associated with the shape of Living Cosmos, which is presented in the mythical narratives characteristic for the archaic culture.

This model of the Living Cosmos is described by Mircea Eliade and other religious scholars, who point toward several features characteristic for this model and they underline the following issue: primarily that this model is tripartite mostly and it includes Earth and the afterlife, i. e. heaven and hell. According to Lenoir it is also possible to make distinction into the lunar world, the world under the moon and the world above the moon. [Lenoir, 2002: 1531-1636]. These worlds are combined by axis mundi inaugurating communication and travelling between them. This allows not only the expedition of heroes into the afterlife, but also the entry into the human world of numinous beings.

One of the essential features of this model is the permanent tension between the chaos that is primary to the Living Cosmos and the Cosmos. This tension ultimately determines the fate of the Cosmos and the style of its existence. It is extremely important that the Universe in this model is inhomogeneous, which gives the possibility of constant interference of numinous forces in its functioning. Here the most important feature of this model appears. This source is inherent for the activity of the sacred, which means that the order of existence is founded 
in sacred reality as a higher order of reality. The wholeness is based on a specific preestablished harmony that assumes the primacy of good over evil, or the equivalence of forces of creation and destruction. The most important feature of this model of Living Cosmos is the rule of harmony that combines creation with destruction and isolates this area from the field of chaos. This model should be supplemented with the entire advanced theological structure characteristic of monotheistic religions [Ouaknin, 2006] and such works as the famous Somnium Scipionis [Macrobius, 1848] Cicero. In the case of monotheistic religions, it is important to introduce metaphysical speculative approaches that adopt the model of the One Creator as the Aristotelian First Cause. On the other hand, Somnium Sciponis, with its concept of the Cosmos, has shaped the imagination of the inhabitants of Europe for centuries, as Carl Staples Lewis wrote about [Lewis, 2008].

The second model is connected with the practice of the rationality referring to the world and contains both the texts of presocratics and Aristotle as well as all subsequent works functioning in this cognitive paradigm.

In this context, we could speak about two basic sources of imagination. The first one is connected with myths and assumes a pre-established harmony. This source of imagination may lead to the production of metaphysical schemes in the type of Porphyry's tree characteristic of Aristotelian-Thomistic metaphysics and ultimately referring to religious experience. The second source whereas is responsible for the vision of a homogeneous universe (in a sense that no "invasive sacrum" may fund it), equally important is that it does not affect its mode of existence. Both of these models could be used independently or in hybrid combinations in artistic practice.

At the same time, it should be pointed out that the mythological model is most often used in fantasy novels, whereas the model based on scientific and non-religious cognition usually appears in SF novels.

\section{The consequences of inhomogeneity of the Universe in fantasy}

The essence of the depictions of the Cosmos in fantasy novels is ambiguous. Authors, who are referring to mythical heritage, use several types of ways for implementing different models of the Cosmos to the world of literary and cinema fiction. However, one can point to a few basic types that appear in the works based on the mythical images of the Living Cosmos.

The first of them is connected with the indication of the beginning of the Universe. Here we have several models, which are based either on the idea of the primacy of chaos against the Cosmos or on the Judeo-Christian concept of creatio ex nihilo. The last one assumes the primacy of the God Creator over the cosmos.

The motif of chaos is often used in the description of the beginning of Universe. It may be a reference to the Sumerian-Babylonian plots in which deities emerge from chaos, as is the case in Dark Materials [Pullman, 1995-2000] and then they undertake creation activity. In addition, it might be a model in which supernatural beings start to limit the impact of chaos and as a result of such type of activity they establish existence of the Universe. This model is realized in three novels of the Amber Chronicle series [Zelazny, 1970-91]: The Courts of Chaos [Zelazny 1978], Prince of Chaos [Zelazny 1991], A sign of Chaos [Zelazny 1987]. Similar themes are at the heart of the Marvel comic series and next in movies series about Thor and his father struggling with the powerful forces of evil in the name of order and peace. This is particularly vividly presented in the movie titled Thor: The Dark World (2013, dir. Alan Taylor) and Thor Ragnarok (2017, dir. Taika Waititi), as well as the Guardians of the Galaxy (2014, dir. James Gunn). 
The third model that implements chaos is connected with the destructive power that leads to the destruction of the order of the Universe. This destruction could be portrayed as the disintegration of the physical structures of the world [Zelazny, 1981], or the emergence of a new model based on the management of the Universe through the forces of chaos. In this case, we have two types of using this motif. The first one is based on bringing chaos to the axiological level (Hjörward Chronicles) [Pierumow, 1995] whereas the second one actualizes a specific amorphism that arises from the lack of rules organizing the existence in the cosmos (Other Songs) [Dukaj, 2003]. The motive of chaos is linked to the images of the Cosmos on the basis of strong antagonism. What is chaotic may even be more primordial than the cosmos itself, but remaining amorphous, it does not assume any orderly shape. Therefore, the mythopoeic mechanisms, which create an imaginary universe, are often based on the mythological archetypes of the extraction of matter from the field of chaos. Also, they could be grounded on the mythological archetypes of limiting the influence of chaos on the process of ordering of the world. This tension between amorphous chaos and the ordered Cosmos could be the basement for different further plots. The universes depicted in them, are not only shown in an antagonized manner and very often axiologically marked, but they allow to create plots in which the functioning of the cosmos is constantly threatened by chaos. Avoiding this threatening and reestablishing order is possible only at the numinous level. In the cinema art it could be noticed in such movies like Avatar (2009, dir. James Cameron), Thor: The Dark World (2013 dir. Alan Tylor) and Thor Ragnarok (2017, dir. Taika Waititi).

Referring to numinous qualities not only allows us to call the Living Cosmos into existence, but also gives it very specific qualities related to the very essence of the Sacredness. The very nature of the sacred, according to the recognition of religious scholars, such as the one already referred to above by Mircea Eliade or Rudolf Otto [Otto, 1993] introduces the division of the universe into two domains: 1) the sacred (numinous), eternal, omnipotent and one which lies beyond human conceiving of good and evil; and 2) profanum remaining in total dependence on the sacred. For this reason, the model of the "invasion of the sacred" which is caused by the Universe's existence and functioning, makes simultaneously responding factors responsible both for its creative and destructive aspects. Therefore, the morphology of the Living Cosmos is dyadic. The first moment is associated with the natural field of the sacred and the second moment is connected with profanum. At the same time, the first one warrants the rules of functioning of the Living Cosmos. For this reason numinous power is indispensable for the existence of this universe, it is necessary to inhomogeneity of its structures, which enables the penetration of power from the Underworld to the human world. This warranting can be reduced to the narrow group of deities merely managing various aspects of the cosmos (Creatures of light and darkness) [Zelazny 1969] or being merely responsible for the order in certain areas of the Living Cosmos assigned to them. The wholeness is usually written into a pre-established harmony model in which all events occurring in the Living Cosmos appear and disappear, e.g. Avatar (2009, dir. James Cameron).

Another aspect of the Living Cosmos associated with trigeminality is the appearance of proto-ideal of parallel worlds, because both Heaven and Hell exist alongside the human world. This idea makes it possible to combine the cycles of eternal return with the idea of eternity, manifested in images of the sky. The man of mythical culture perceives himself as an element of permanent and unchanging presence of stars and in own narratives he combines his temporality with immobility (from his prospect) perfection of the heavens. Both in mythical narratives and mythopoeic fantasy, he appears not only to enter the afterlife, but also like desire about the expedition itself. This inhomogeneity allows the hero to enter the field 
of axis mundi which connecting all the elements of the Living Cosmos and in consequence making a journey to the afterlife, which is the realm of the numinosum.

Forms of mythopoeic renarrations bring a few important aspects of the cosmic image of the Universe based on mythical plots. Its existence is conditioned by a permanent process of separation from the influence of chaos whereas the very act of establishing existence and its principles belongs to the supernatural beings. The Nature of the Living Cosmos is largely determined by the numinous aspect. For this reason, eternality is perfect and exemplary, and everything temporally must take on this pattern. This gives two model dimensions in which the transformation time is unnoticeable to a human being. It is all about the heavens, treated as the domain of deities, and the pattern of everything that exists. For this reason, the original myths link the order of the World with the solstices of the Sun and the cycles of the Moon. Another important aspect of mythical imagery is the cyclical nature of the Cosmos transformations. This nature can be reflected in the stories based on Scandinavian (The Gospel of Loki, 2014) [Harris, 2014] or pre-Columbian mythology (The Crystal skull, 2007) [Scott 2007]. Mythopoeic models of the Living Cosmos evoke various mythical plots: Egyptian (Creatures of light and darkness), Greek (Troy/series, 2005-2007) [Gemmell, 2005-2007], Scandinavian [Gaiman, 2017], Slavic (Bogatyr Trilogy, 2005-2008) [Červenák, 2005-2008] as well as biblical theologians (The ower of the wind/ in polish: Siewca wiatru, 2004) [Kossakowska, 2004]. In cinema, we may observe this formula in the different variants of The Mummy. The first one was just horror (1932, dir. Karl Freund) but the closer to the present day the following version became more and more part of genre of fantasy (The Mummy, 1999, dir. Stephen Sommers, The Mummy Returns, 2001, dir. Stephen Sommers, The Mummy, 2017, dir. Alex Kurtzman).

\section{Discovering the scientific model of the Cosmos}

The introduction of scientific references to the image of the Cosmos to the fantasy begins at the initial stage of the formation of a formula of modern speculative fiction. The best example was The Saragossa Manuscript [Potocki, 1810] written by Jan Potocki, where there are both motifs of the cracked, inhomogeneous Living Cosmos, and the figure of a Jew of Eternal Wandering, whose biological existence was excluded from the influence of time. From the perspective of Enlightenment's rationalism, which was embodied in the art characters who had to face the uncannys, all these motives originated from irrational imaginations of the Cosmos, and characters' aim was to try to seek a rational justification for them. These first attempts includes two important aspects. One of them is the operation of selected motifs of mythical plots, such as the tripartite Cosmos in the prose of Jules Verne. The second could be represented as the searching for a rational explanation of the principles of operation of the Universe without referring to the supernatural order. As a result, mythical motifs become more and more degraded and carriers of meanings and content amenable to rationalization. A classic example of such a procedure is the motif associated with the division of the Cosmos into the Undermoon World, lunar, and above moon zone present in the cited text of Cicero. It was cultural strength of Jan Twardowski that made the witches fly on the Sabbaths, and enabled him to escape from the obligations of the cyrograph to the moon on the rooster. These first explorations of the Cosmos, by nature, are limited to expeditions to the moon, but the technology of these journeys excludes the necessity of using magical and supernatural attributes and uses modified forces of nature in the form of a rooster (it is in scale proper to ride for human). In novel Other World, 1657 by Cyrano de Bergerac this technology appears in the figure of modified geese. Furthermore, the journeys in Cyran 
de Bergerac's novel are already in the lunar world, they even reach the Sun. Additionally, these journeys in consequence open the model of the anthropocentric view of the cosmos by introducing the motifs of the presence of human social structures in space that will appear in subsequent decades both in novels like Aelita, 1923 [Tołstoj, 1923], Andromeda: A SpaceAge Tale, 1957 [Jefremov, 1957] or The Void Trilogy, 2007-2010 [Hamilton, 2007-2010]. In cinema art, we may observe those ideas in one of the first movie project Le voyage dans la lune (The journey to the moon, 1902, dir. Georges Méliès), where this kind of inconceivable but not magical technology is used.

Jules Verne's novels introduce not only the first aspect of space technology in extraterrestrial flights, as can be seen in the novel From Earth to the Moon (De la terre à la lune) [Verne, 1877] full of substantive errors, but like in the other two novels (Around the Moon / Autour de la Lune, 1869) and The world upside down / Sans dessus dessous [Verne, 1889], descriptions presenting the current state of scientific knowledge concerning the cosmos are already appearing. The motifs of the tripartite Cosmos are also changing. First of all, the undergrounds cease to be the domain of supernatural beings and become a space inhabited by beings from the Mesozoic era who avoided the cataclysm and the great extinction associated with it (Journey to the inside of the Earth / Voyage au centre de la Terre, [Verne, 1864]. And, secondly, the heavens are no longer inhabited by deities but creatures similar to people or just by people (A Princess of Mars) [Burroughs, 1912]. This introduction of the anthropocentric concept of the Cosmos, however, does not rule out the complete rejection of the motives of presence of the supernatural beings in the universe.

A very interesting example is the proposition of Howard Philips Lovecraft [Lovecraft, 1926], who modified the concept of evolution of the Universe present in the gnosis and then introduced various stages of the development of the Cosmos divided into eons and also assigned to them different beings from our biology. He introduced thus a cyclical concept of time into the eternal cosmos. Its scientific version will be created many years later by Roger Penrose (Cycles of Time: An Extraordinary New View of the Universe) [Penrose, 2011]. Thus, we may notice the process of reduction of the mythological models in the sciencefiction. This inevitably leads to an ever-stronger emphasis on the rationalization of the forms of the universe. Initially, journeys to the moon do not differ from the earthly ones, but the real knowledge of the cosmos gradually becomes part of the fantastic's universe. The difference between the cosmic and earths reality can be experienced by viewers for the first time in the movie Women in The Moon (1929, dir. Fritz Lang), and the best expression of this tendency is the latest production Gravity (2013, dir. Alfonso Cuaron).

However, its initial stages of development, strongly motivated by rules of the market, led to dominating position of the young reader. The effects were not only progressing infantilization and trivialization, but also increasing primacy of an adventure perspective in cultural industry.

Fortunately, this model, focused on teenage readers, has not proved to be permanent and the science fiction was continuing the work initiated by Jules Verne, who was implementing the latest scientific discoveries into cultural images of the Cosmos. Until lately, the scientific discoveries have been not understandable to a wide range of popular culture participants, most often because of these discoveries' complex structure. Especially in literary texts, they had a completely different character, forcing the audience to expand the colloquial and nonscientific perception of the World. Consequently, writers are not only dispensing with the model of the Living Cosmos, but are focusing on the universe, which is, more and more based on subsequent scientific discoveries. 
It is difficult to talk about some uniform type of poetics here. We would like to point out these aspects of contemporary scientific discoveries concerning the Universe, which appear in popular culture. They could be divided into several basic types. The first one concerns on the very mechanism of existence of the Universe and its construction. The second one raises the issues of mathematical trimmines and related to it rationalities of the mathematical type that is are present in the structure of the Universe. The third one relates to the issue of life in space and the last one takes the purposefulness of the Universe. The motifs, which are related to the very construction of the Cosmos, were developed in parallel to the very understanding of the size of the Universe. In the initial version, indefinite characteristic distances and sizes appeared, for example, in the descriptions made by Cicero. However, later, starting with Jules Verne the process of introduction of more precise descriptions of the size, first within the Solar System, has begun. With the appearance of the novel Arthur C. Clarke [Clark, 1968] and Edward Smith Elmer's "Doc" [Smith, 1950] the motives of interstellar, furthermore, intergalactic structures were introduced. However, the merit of discovery of deep space belongs to the space-operas authors. The introduction of the deep space theme was associated with the issue of space travel in distances unimaginable to the recipient of popular culture, which had to be closed in certain limited time of story. This has led, on the one hand, to the emergence of a very important motif of space travel themselves, and, on the other hand, to the introduction of two new elements that constitute the artistic depictions of the Cosmos. The first is related to the concepts of the wormhole, which for example in the Takeshi Kovacs trilogy [Morgan, 2002-2005], and the second introduces concepts of parallel worlds. However, two important modifications are introduced in the second concept. The first is that there is a technical possibility of penetrating matter between parallel universes (The gods themselves) [Asimov, 1972] or even traveling between them. The second one takes up the question of the difference not only in the construction, which is reduced to the atomic level (The gods themselves) or also physico-biological (cycle Agent John Francis Kovár̆) [Żamboch, 20052007]. Another important element in the structure of the Cosmos is the introduction of a two-dimensional compact topological manifold in the form of the Möbius Ribbon to describe possible journeys in time treated artistically as an infinite continuum (the Necroscope cycle) [Lumley, 1986-2013]. The space-opera authors often have used the motif of black holes not only as elements forming the galaxy structures, but above all as a mysterious phenomenon that creates various possibilities of fantastic speculations related to the gravitational collapse or even more intriguing motif of the event horizon surrounding black holes (The Void Trilogy) [Hamilton, 2007-2010]. The most recent novels and movies has already introduce elements of quantum physics with all the consequences concerning the account of time, space and consciousness, it is even more interesting that writers who undertake such operations are themselves mostly quantum physicists with scientific titles, such as Hannu Rajaniemi (Jean le Flambeur, 2010-2014 ). What best showed the creators of the Star Trek series (The Original Series 1966-1969; 987-1994, Star Trek: The Next Generation, 1987-94; Star Trek: Deep Space Nine,1993-1999; Star Trek: Voyager, 1995-2001; Star Trek: Enterprise, 20012005; Star Trek: Discovery; 2017-2019) with their attachment to scientific truth and the latest discoveries in the field of astronomy, quantum physics, cosmology, etc. One of the last attempts of such an approach was the movie Interstellar (2014, dir. Christopher Nolan). The problem of curving space-time and time loops introduces into his vision of the cosmos Charles Yu in his novel How to Live Safely in a Science Fictional Universe, 2010, where he tackles the problem of the reversibility of events in the time perspective. The last example of the introduction of scientific motifs into popular culture concerns the novels written by 
Nancy Kress, and especially one of them, Probability Space, 2002, in which literary projects of random events fit into the structurally sketched random structure of elementary events, what in turn leads to the emphasis on not only mathematical character of a certain aspect of events in space, but also on the random nature of entire human existence and reality.

The most interesting seems to be that the use of literary mechanisms exploiting scientific content to build cosmic images expresses the speculative function of literature in the best way. It is here that the most common issues arise, in which mathematics, physics and astronomy have not yet achieved fully satisfactory results. It may concern, for example, the issues of technological adoption of black holes (The Void Trilogy) of time travel (How to survive in a science-fiction universe) or creation of wormholes (Takeshi Kovacs) or exploration of parallel worlds (Agent John Francis Kovár). The first and classic example of a speculative function in a described dimension for instance according to the philosophy of nature in terms of Michat Heller [Heller, 2008] is a great novel by Stanistaw Lem "The Investigation" (1959), in which we can deal with a problem of mathematical rationality of the Cosmos, which is not understandable for the human intellectual, what turns out to be the main problem among the conceptions of the philosophy of nature considering the question of the rationality of the type of mathematical universe. Another issue very readily undertaken by writers and directors is the issue of the origin of life in space. In this case, we have to deal with the most trivial ideas assuming a classic anthropocentric model, through proposals in which life arises not only on the basis of carbon compounds, but even quartz. Also, we are able to observe such models, in which man is presented as one of many representatives of the races minded. Additionally, the logical thinking mechanism itself does not necessarily have to be related to the Earth's scientific tradition. In this diversity of life and thinking two important issues appear. The first concerns the mechanisms of terraforming worlds (Startide Rising) [Brin, 1983]. In movies, we can see his process in such productions like Star Trek: The Next Generation, Doctor Who episode: "The Doctor's Daughter" (2008), Total Recall (1990, dir. Paul Verhoeven), Stargate SG-1 episode "Scorched Earth" (2000).

The most interesting speculative models refer to both scientific and mythical (characteristic for living religions) matrices. We can point out several basic types of strategies in popular culture. In these circumstances, the existence of God is part of the order of the metaphysically conceived Universe. It turns out that the death of God does not necessarily mean the end of the Universe, nor the end of entanglement of human choices into the horizon of good and evil (J. Morrow — Towing Jehovah, 1994, Blameless in Abaddon, 1996). The second is related to the combination of high technologies with numinous elements, as is the case with Roger Zelazny (Jack of Shadows, 1972) or also quasi-numinous (Dune) [Herbert, 1965]. Another procedure of building the cosmic worlds is based on models that were constructed in the past and which, although they have been remaining logically coherent, do not present the real universe, as it is in the case of the Aristotelian treatise On the sky [Aristotle, 1990], which, on the other hand, becomes the basis for the construction of the world presented for example in (Other Songs/ Inne pieśni, 2003) by Jacek Dukaj. An interesting procedure is also the attempt to search a sources of moral order in the Universe, especially in those projects in which the numinous dimension of creation is excluded. It seems, however, that even in this case we are dealing with the reduction of a certain mythical model to the physical level, which is best exemplified in Star Wars (Star Wars. Episode IV - A New Hope, 1977, dir. George Lucas; Episode V - The Empire Strikes Back, 1980, dir. Irvin Kershner; Episode VI — Return of the Jedi, 1983, dir. Richard Marquand) with the dark and light side motive. 


\section{Conclusions}

The depictions of the Cosmos are represented in popular culture as a complicated network of references and interactions. They remain in close connection with contemporary condition of scientific research in the field of sciences as well as with broadly religious and anthropology reflection. Symptomatic is that the progressing complexity of images of the Universe show the three types of artistic strategies. We can call the first one as the adventure, which treats the cosmos as a background for human expansion and simultaneously introduces the theme of other forms of life and first contact. The second one is focused on the religious imaginations. It is testing not only various forms of religious experience, but the supernatural purposefulness of human existence and its relationship with the nature of the Cosmos as well. The third one considers the mystery of the Cosmos from rational point of view. Thus, the Cosmos in popular culture is becoming more and more as an open space as well as a challenge. This is closely related to the fact that all popular culture images in some way remain closed in the anthropocentric paradigm, which could not be any more identified with the original, infantile anthropocentrism of science fiction.

\section{References}

Aristotle, On the Heavens [in:] Collected works, vol. 2, Physics, polish translation by K. Leśniak, Warszawa 1990.

Asimov, Isaac. The gods themselves, London 1972.

Bazaluk, Oleg. The Feature Transformations of the Basic Meanings of Greek Paideia in the Educational Theories in the Middle Ages. $\mathrm{XO} \Lambda \mathrm{H}, 12(1), 2018: 243-258$. https://doi. org/10.21267/AQUILO.2018.12.10428

Bergerac, Cyrano de. Other worlds: the comical history of the states and empires of the moon and sun (1657)/ translated and with an introduction by Geoffrey Strachan. London 1976.

Brin, David. Startide Rising, Bantam, 1985.

Burroughs, Edgar. Rice. A Princess of Mars, 1912.

Caillois Roger. At the heart of the fantastic [Au coeur du fantastique], 1965, polish translation by M. Ochab, Gdańsk, 2005.

Červenák, Juraj. Bogatyr Trilogy, 2005-2008.

Clarke, Arthur. C. 2001: A Space Odyssey, 1968.

Dukaj, Jacek. Inne pieśni (Other Songs), Krakow 2003.

Eliade Mirecea. A history of religious ideas [Traité d'histoire des religions], polish translation by J. Wierusz-Kowalski, Łódź 1993.

eNotes: Differentiate between fancy and imagination as proposed by Samuel Taylor Coleridge. eNotes, 15 Mar. 2010, https://www.enotes.com/homework-help/differentiate-fancyimagination-proposed-by-samuel-147885 [access 6 Sep. 2018].

Gaiman, Neil. Norse Mythology, London 2017.

Gemmell, David. Troy/series, 2005-2007.

Hamilton, Peter F. The Void Trilogy, London 2007-2010.

Harris, Joanne. The Gospel of Loki, London 2014.

Heller, Michat. Philosophy and the universe, Kraków 2008. (in Polish language).

Herbert, Frank. Dune, London 1965.

Jefremov, Ivan. Andromeda: A Space-Age Tale/ Туманность Андромеды / Moskva 1957.

Kress, Nancy. Probability Space, 2002. 
Kossakowska, Maja Lidia. The sower of the wind/ Siewca Wiatru, Lublin 2004.

Lem, Stanisław. Investigation / Śledztwo, Kraków 2016.

Lenoir, Frederic, Tardan-Masquelier, Ysé (ed). Encyclopedia of World Religions, vol.2 Main

Problems, polish translation by others, Warszawa 2002: 1531-1636.

Liashenko, Iryna. Wilhelm Dilthey: Understanding the Human World. Philosophy and Cosmology, Volume 20, 2018: 163-169. https://doi.org/10.29202/phil-cosm/20/16/

Lovecraft, Howard. Phillips. The Call of Cthulhu, London 2016.

Lumley, Brian. Necroscope cycles, vol. 1-18, London 1986-2013.

Morgan, Richard K. Takeshi Kovacs, vol. 1-3., London 2002-2005.

Morrow, James K. Towing Jehovah, 1994, Idem, Blameless in Abaddon, 1996.

Otto, Rudolf. Holiness: Irrational elements in the concept of a deity and their attitude to rational elements [Das Heilige - Über das Irrationale in der Idee des Göttlichen und sein Verhältnis zum Rationalen], polish translation by B. Kupis, Wrocław 1993.

Ouaknin, Marc-Alain, Mysteries of Kabbalah [Mystères de la Kabale], polish translation by K. and K. Pruscy, Warszawa 2006.

Penrose, Roger. Cycles of Time: An Extraordinary New View of the Universe, polish translation by B. Bieniok, E. Łokas, Warszawa 2011.

Perumov, Nik. Hjorward Chronicles, Vol. 1-3/ Хроники Хьерварда, 1994-1995.

Polischuk, Olena. Artistic Myth and its Interpretations of Cultural Heritage of the Eastern European Countries in the Popular Animated Films of the Post-Soviet Period. Future Human Image, Volume 10, 2018: 62-69. https://doi.org/10.29202/fhi/10/6

Potocki, Jan. The Manuscript found in Saragossa/ in oryg. Manuscrit trouvé à Saragossem, Penguin 2006.

Pryhodko, Volodymyr and Sergii Rudenko. Body and Space Relationship in the Research field of Phenomenological Anthropology: Blumenberg's Criticism of Edmund Husserl's “Anthropology Phobia". Anthropological Measurements of Philosophical Research, Volume 13, 2018: 30-40. https://doi.org/10.15802/ampr.v0i13.125512

Pullman, Philip. His Dark Materials, vol. 1-3, London 2015.

Rajaniemi, Hannu. Jean le Flambeur, vol. 1-3 (The quantum thief, 2010; The fractal prince, 2012; The Causal Angel, 2014).

Scott, Manda. The Crystal skull, London 2007.

Smith, Edward. Elmer "Doc". First Lensman, 1950.

Tołstoj, Aleksy. Aelita, 1923.

Verne, Jules. From Earth to the Moon (De la terre à la lune), 1877; Around the Moon / Autour de la Lune, 1869; The world upside down / Sans dessus dessous, 1889; Journey to the inside of the Earth / Voyage au centre de la Terre, 1864.

$\mathrm{Yu}$, Charles. How to survive in a science-fiction universe, London 2010.

Zelazny, Roger. Creatures of light and darkness, 1969; Amber Chronicle, series, 1970-1991; Jack of Shadows, 1972; The Courts of Chaos, 1978; The Changing Land, 1981; A Sign of Chaos, 1987; Prince of Chaos, 1991.

Žamboch, Miroslav; Procházka, Jiri W.; Schink, Petr; Némec, Tomas. Agent John Francis Kováŕ, vol. 1-8, 2005-2007. 